\title{
Spectral reflectance indices as proxies for yield potential and heat stress tolerance in spring wheat: heritability estimates and marker-trait associations
}

\author{
Caiyun LIU ${ }^{1}$, Francisco PINTO (凶) ${ }^{1}$, C. Mariano COSSANI ${ }^{2,3}$, Sivakumar SUKUMARAN (ه) ${ }^{1}$, \\ Matthew P. REYNOLDS ${ }^{1}$
}

1 International Maize and Wheat Improvement Center (CIMMYT), Texcoco 56237, Mexico

2 South Australian Research and Development Institute-SARDI, Adelaide 5001, Australia

3 School of Agriculture, Food and Wine, The University of Adelaide, Urrbrae SA 5064, Australia

\begin{abstract}
The application of spectral reflectance indices (SRIs) as proxies to screen for yield potential (YP) and heat stress (HS) is emerging in crop breeding programs. Thus, a comparison of SRIs and their associations with grain yield (GY) under YP and HS conditions is important. In this study, we assessed the usefulness of 27 SRIs for indirect selection for agronomic traits by evaluating an elite spring
\end{abstract} wheat association mapping initiative (WAMI) population comprising 287 elite lines under YP and HS conditions. Genetic and phenotypic analysis identified 11 and 9 SRIs in different developmental stages as efficient indirect selection indices for yield in YP and HS conditions, respectively. We identified enhanced vegetation index (EVI) as the common SRI associated with GY under YP at booting, heading and late heading stages, whereas photochemical reflectance index (PRI) and normalized difference vegetation index (NDVI) were the common SRIs under booting and heading stages in HS. Genomewide association study (GWAS) using 18704 single nucleotide polymorphisms (SNPs) from Illumina iSelect 90K identified 280 and 43 marker-trait associations for efficient SRIs at different developmental stages under YP and HS, respectively. Common genomic regions for multiple SRIs were identified in 14 regions in 9 chromosomes: 1B (60-62 cM), 3A (15, 85-90, 101$105 \mathrm{cM}), 3 \mathrm{~B}(132-134 \mathrm{cM}), 4 \mathrm{~A}(47-51 \mathrm{cM}), 4 \mathrm{~B}(71-$ $75 \mathrm{cM}), 5 \mathrm{~A}(43-49,56-60,89-93 \mathrm{cM}), 5 \mathrm{~B}(124-125 \mathrm{cM})$, 6A (80-85 cM), and 6B (57-59, $71 \mathrm{cM})$. Among them, SNPs in chromosome 5A $(89-93 \mathrm{cM})$ and $6 \mathrm{~A}(80-85 \mathrm{cM})$ were co-located for yield and yield related traits. Overall, this study highlights the utility of SRIs as proxies for GY under YP and HS. High heritability estimates and identification of marker-trait associations indicate that

Received March 28, 2019; accepted April 29, 2019

Correspondences: Fr.Pinto@cgiar.org, S.Sukumaran@cgiar.org
SRIs are useful tools for understanding the genetic basis of agronomic and physiological traits.

Keywords genome-wide association study (GWAS), heat tolerance, spectral reflectance, spring wheat

\section{Introduction}

Bread wheat (Triticum aestivum L.) is one of the staple food crops in the world providing $20 \%$ of the proteins and calories to the world population; increasing grain yield (GY) of spring wheat is therefore important for world food security ${ }^{[1]}$. Short episodes of extreme heat are expected to become more frequent, which could have adverse impacts on yield ${ }^{[2]}$. Conventional breeding based on the selection of yield per se has been very efficient in raising wheat production under irrigated conditions in the past ${ }^{[3]}$. However, the estimation of GY requires the harvest of the experimental plots, which is expensive and timeconsuming at a breeding scale ${ }^{[4]}$. The identification of proxies for GY in early stages of crop growth can increase the efficiency of selection and reduce the number of plots harvested ${ }^{[5]}$. Use of morphological and physiological traits as indirect selection criteria for GY is an alternative breeding approach ${ }^{[6]}$. In recent years, spectroradiometry has offered a quantum leap forward in the efficiency of screening physiological traits that have been typically laborious and time-consuming ${ }^{[7-9]}$. The prospect of future genetic improvements using spectral reflectance to identify and track physiological traits, offers crop breeding programs new opportunities to increase yield potential (YP) and to improve wheat to abiotic stresses such as heat stress (HS) ${ }^{[10,11]}$.

The spectral reflectance of a canopy is directly linked to a plant's biophysical and biochemical properties, which 
determine absorption and reflection patterns at specific wavelengths ${ }^{[12]}$. Pigments in leaves absorb light strongly in the visible spectrum (VIS, 380-740 $\mathrm{nm}$ ) rather than the near-infrared region (NIR, $740-2500 \mathrm{~nm})^{[10]}$, resulting in a different reflection of radiation in the two regions. Spectral reflectance indices (SRIs) represent the simplest way to obtain information from spectral reflectance measurements and were developed using simple mathematical formulae such as ratios or differences between reflectances observed at different wavelengths. The simple ratio (SR) index ${ }^{[13]}$ and the normalized difference vegetation index (NDVI) ${ }^{[14]}$ were the first SRIs to be described and are commonly used to predict green biomass and green leaf area index. Some SRIs use only reflectance at the VIS wavelentghs, such as the photochemical reflectance index (PRI) which is used to assess radiation-use efficiency ${ }^{[15]}$; or only NIR, such as the water index (WI) that is related to water status of the canopy ${ }^{[16,17]}$. SRIs have been widely used in assessing different physiological conditions of the canopy such as the estimation of total dry matter, leaf area index, photosynthetic capacity, and pigment concentration ${ }^{[18-21]}$. GY has also been frequently estimated using SRIs measured at different growth stages of the wheat crop under irrigated and water-limited environments ${ }^{[22-26]}$.

SRIs may be related to complex quantitative traits controlled by multiple genetic factors. Recent studies identified the genomic regions for several SRIs under fully irrigated, rainfed, and drought-stressed environments in bread wheat ${ }^{[27,28]}$. However, little is known about the genomic regions associated with SRIs in spring wheat under HS. In the present study, a spring wheat association mapping initiative (WAMI) panel was phenotyped under YP and HS conditions. The objectives of this study were to (1) identify efficient SRIs as proxies for GY under YP and HS environments, and (2) identify the genomic regions associated with SRIs for YP and HS through genome-wide association study (GWAS).

\section{Materials and methods}

\subsection{Germplasm, genotyping, and population structure}

The WAMI panel consisting of 287 elite spring wheat lines was assembled at the International Maize and Wheat Improvement Center (CIMMYT) for dissecting the genetic basis of complex traits. This is a collection of elite lines assembled from the international nurseries that CIMMYT distributes to developing countries through the International Wheat Improvement Network (IWIN). The material was genotyped using the Illumina iSelect $90 \mathrm{~K}$ single nucleotide polymorphism (SNP) array. A total of 21871 assays showed three distinct clusters corresponding to the $\mathrm{AA}, \mathrm{AB}$, and $\mathrm{BB}$ genotypes expected for a biallelic SNP. Of the remaining assays with poorer cluster separation, manual clustering was applied. Overall, 36133 of the 81587 functional SNPs visually revealed polymorphism among the WAMI population. We were able to locate $28614(35.1 \%)$ of the SNPs on the published genetic map $^{[29]}$. After removing SNPs with minor allele frequency $<5 \%$ and missing value $>10 \%, 18704$ SNPs were used for GWAS. The population structure of the panel was associated with pedigree of the lines. A detailed description of the population structure, linkage disequilibrium, and minor allele frequency can be found in earlier studies of the WAMI population ${ }^{[30-32]}$.

\subsection{Field experiment and agronomic practices}

Field trials were conducted during the 2015-2016 crop season under field conditions at Campo Experimental Norman E. Borlaug (CENEB), Ciudad Obregon, Yaqui Valley, Mexico $\left(27^{\circ} 25^{\prime} \mathrm{N}, 1^{\circ} 9^{\circ} 54^{\prime} \mathrm{W}, 38 \mathrm{masl}\right)$. The WAMI population was phenotyped in a randomized lattice design with two replications under YP and HS. The YP environment was simulated by planting in late November and full irrigation (total water supply $>700 \mathrm{~mm}$ ) was provided. HS was applied by late sowing (late February) with full irrigation (total water supply $>700 \mathrm{~mm}$ ) to avoid the effect of drought; a typical method for applying HS at CENEB that has been demonstrated to be successful in generating germplasm for HS environments such as $\mathrm{ME}^{[33]}$. Seeds were sown on raised beds $2 \mathrm{~m}$ long with two rows $(25 \mathrm{~cm}$ between rows) and $80 \mathrm{~cm}$ between the beds. Appropriate fertilizers, pesticides, and insecticides were applied according to normal practices prevalent in this region.

\subsection{Phenotypic traits measurement}

A high-resolution spectroradiometer (FieldSpec ${ }^{\circledR}$ HandHeld 2, ASD Inc., Longmont, CO, USA) was used to measure the spectral reflectance of each plot. The HandHeld 2 is a hand-held spectro-radiometer that uses a FieldSpec 4 VNIR spectrometer for accurate analysis in the 325-1075 nm spectral range. To collect one spectral measurement, the sensor was located $50 \mathrm{~cm}$ over the canopy pointing in nadir position. A $12.7 \mathrm{~cm} \times 12.7 \mathrm{~cm}$ calibrated white panel $\left(99 \%\right.$ Spectralon ${ }^{\circledR}$, Labsphere Inc., North Sutton, NH, USA) was used for the estimation of the incoming radiation and the spectral reflectance. An average spectrum per plot was estimated using four measurements collected at different locations across the plot and avoiding the first $50 \mathrm{~cm}$ at each extreme of the plot. The spectral measurements were conducted at 11:00-14:00 to avoid the possibility of confounding effects from variations in solar radiation. The spectral measurements were conducted at booting (Zadok 50), heading (Zadok 60), and 7 days after heading (heading plus 7 days, H7) stages in the YP environment, while in HS they were conducted at booting 
(Zadok 50) and heading (Zadok 60) stages. Several SRIs were derived from the collected data. The names, formulas and references can be found in Table 1 .

In addition to SRIs, the following agronomic traits were measured: GY $\left(\mathrm{g} \cdot \mathrm{m}^{-2}\right)$, thousand-grain weight (TGW, g), grain number [GN, estimated as GY $\left(\mathrm{g} \cdot \mathrm{m}^{-2}\right) / \mathrm{TGW}(\mathrm{g}) \times$ 1000], days to heading (DTH, i.e., the number of days from emergence when $50 \%$ of the spikes had emerged); days to maturity (DTM, i.e., the number of days from emergence to when the kernel became hard); plant height $(\mathrm{PH}, \mathrm{cm}$, from the soil surface to the tip of the spike without awns).

\subsection{Statistical analysis}

The best linear unbiased prediction (BLUP) values for agronomic traits and SRIs were calculated using META$\mathrm{R}^{[50]}$. Correlations between the traits were estimated using SAS v9.1 (SAS Institute, Cary, CA, USA). Broad sense heritability $\left(H^{2}\right)$ was estimated as:

Table 1 SRIs measured on the WAMI population under YP and HS environments in Ciudad Obregon, Mexico during the 2015-2016 growing season

\section{SRIs}

Vegetation indices

Simple ratio (SR)

Normalized difference vegetation index_670 (NDVI_670)

Normalized difference vegetation index_670 (NDVI_705)

Enhanced vegetation index (EVI)

MERIS terrestrial chlorophyll index 1 (MTCI1)

MERIS terrestrial chlorophyll index 2 (MTCI2)

Optimized soil adjusted vegetation index (OSAVI)

Transformed chlorophyll absorption in reflectance index (TCARI)

Water indices

Water index (WI)

Normalized water index_1 (NWI_1)

Normalized water index_2 (NWI_2)

Normalized water index_3 (NWI_3)

Normalized water index_4 (NWI_4)

Red edge indices

Normalized phaeophytinization index (NPQI)

Chlorophyll indices

Chlorophyll ratio (AB ratio)

Ratio analysis of reflectance spectra for chlorophyll a (RARSa)

Ratio analysis of reflectance spectra for chlorophyll b (RARSb)

Ratio analysis of reflectance spectra for carotenoids (RARSc)

Pigment specific simple ratio a (PSSRa)

Anthocyanin reflectance index 1 (ARI1)

Anthocyanin reflectance index 2 (ARI2)

Carotenoid reflectance index 1 (CRI1)

Carotenoid reflectance index 2 (CRI2)

Caroenoide

Normalized difference pigment index (NDPI)

Plant senescence reflectance index (PSRI)

Structure insensitive pigment index 2 (SIPI2)

Radiation use efficiency

Photochemical reflectance index (PRI)
Equation

$$
\begin{gathered}
\mathrm{R}_{\mathrm{NIR}} / \mathrm{R}_{\mathrm{RED}}{ }^{[34]} \\
\left(\mathrm{R}_{780}-\mathrm{R}_{670}\right) /\left(\mathrm{R}_{780}+\mathrm{R}_{670}\right)^{[14]} \\
\left(\mathrm{R}_{750}-\mathrm{R}_{705}\right) /\left(\mathrm{R}_{750}+\mathrm{R}_{705}\right)^{[37]} \\
2.5\left(\mathrm{R}_{\mathrm{NIR}}-\mathrm{R}_{\mathrm{RED}}\right) /\left(\mathrm{R}_{\mathrm{NIR}}+6 \mathrm{R}_{\mathrm{RED}}-7.5 \mathrm{R}_{\mathrm{BLUE}}+1\right)^{[38]} \\
\left(\mathrm{R}_{754}-\mathrm{R}_{709}\right) /\left(\mathrm{R}_{709}-\mathrm{R}_{681}\right)^{[39]} \\
\left(\mathrm{R}_{\mathrm{NIR}}-\mathrm{R}_{748}\right) /\left(\mathrm{R}_{748}-\mathrm{R}_{\mathrm{RED}}\right)^{[39]} \\
\left(\mathrm{R}_{\mathrm{NIR}}-\mathrm{R}_{\mathrm{RED}}\right) /\left(\mathrm{R}_{\mathrm{NIR}}+\mathrm{R}_{\mathrm{RED}}+0.16\right)^{[42]} \\
3\left(\left(\mathrm{R}_{700}-\mathrm{R}_{670}\right)-0.2\left(\mathrm{R}_{700}-\mathrm{R}_{550}\right)\left(\mathrm{R}_{700} / \mathrm{R}_{670}\right)\right)^{[43]}
\end{gathered}
$$

$$
\begin{gathered}
\mathrm{R}_{970} / \mathrm{R}_{900}{ }^{[45]} \\
\left(\mathrm{R}_{970}-\mathrm{R}_{900}\right) /\left(\mathrm{R}_{970}+\mathrm{R}_{900}\right)^{[23]} \\
\left(\mathrm{R}_{970}-\mathrm{R}_{850}\right) /\left(\mathrm{R}_{970}+\mathrm{R}_{850}\right)^{[23]} \\
\left(\mathrm{R}_{970}-\mathrm{R}_{880}\right) /\left(\mathrm{R}_{970}+\mathrm{R}_{880}\right)^{[47]} \\
\left(\mathrm{R}_{970}-\mathrm{R}_{920}\right) /\left(\mathrm{R}_{970}+\mathrm{R}_{920}\right)^{[47]} \\
\left(\mathrm{R}_{415}-\mathrm{R}_{435}\right) /\left(\mathrm{R}_{415}+\mathrm{R}_{435}\right)^{[49]}
\end{gathered}
$$

$$
\begin{gathered}
\text { RARSa/RARSb }{ }^{[35]} \\
\mathrm{R}_{675} / \mathrm{R}_{700}{ }^{[36]} \\
\left(\mathrm{R}_{675} / \mathrm{R}_{650} \times \mathrm{R}_{700}\right)^{[36]} \\
\mathrm{R}_{760} / \mathrm{R}_{500}{ }^{[36]} \\
\mathrm{R}_{800} / \mathrm{R}_{680}{ }^{[40]} \\
1 / \mathrm{R}_{550}-1 / \mathrm{R}_{700}{ }^{[41]} \\
\mathrm{R}_{800}\left(\left(1 / \mathrm{R}_{550}\right)-\left(1 / \mathrm{R}_{700}\right)\right)^{[41]} \\
1 / \mathrm{R}_{510}-1 / \mathrm{R}_{550}{ }^{[44]} \\
1 / \mathrm{R}_{510}-1 / \mathrm{R}_{700}{ }^{[44]}
\end{gathered}
$$

$$
\begin{gathered}
\left(\mathrm{R}_{680}-\mathrm{R}_{430}\right) /\left(\mathrm{R}_{680}+\mathrm{R}_{430}\right)^{[45]} \\
\left(\mathrm{R}_{680}-\mathrm{R}_{500}\right) / \mathrm{R}_{750}{ }^{[46]} \\
\left(\mathrm{R}_{800}-\mathrm{R}_{445}\right) /\left(\mathrm{R}_{800}+\mathrm{R}_{680}\right)^{[48]}
\end{gathered}
$$

$$
\left(\mathrm{R}_{531}-\mathrm{R}_{570}\right) /\left(\mathrm{R}_{531}+\mathrm{R}_{570}\right)^{[15]}
$$

Note: SRIs, spectral reflectance indices; WAMI, wheat association mapping initiative; YP, yield potential; HS, heat stress; $\mathrm{R}_{\mathrm{NIR}}$, average reflectance between 780 and $900 \mathrm{~nm} ; \mathrm{R}_{\mathrm{RED}}$, average reflectance between 670 and $690 \mathrm{~nm}$; $\mathrm{R}_{\mathrm{BLUE}}$, average reflectance between 459 and $479 \mathrm{~nm}$. 


$$
H^{2}=\frac{\sigma_{g}^{2}}{\sigma_{g}^{2}+\frac{\sigma_{e}^{2}}{r}}
$$

where $\sigma_{g}^{2}$ and $\sigma_{e}^{2}$ were genotype and error variance, and $r$ was the number of replications.

For the selection of efficient SRIs that could predict GY, two steps of analysis were conducted: (1) to identify the SRIs that were significantly correlated with GY $(P<0.01)$ at different crop stages; (2) to remove redundant SRIs based on correlations and only keeping those with relative highest $H^{2}$ in the same correlation cluster.

\subsection{Marker trait associations (MTAs)}

GWAS analysis was performed in TASSEL v5.0 software using the generalized linear model and mixed linear model ${ }^{[51]}$. Models were compared by fitting simple model, familial relatedness matrix $(\mathrm{K})$ as random factor, population structure $\left(\mathrm{Q}_{1}-\mathrm{Q}_{10}\right)$ from STRUCTURE, principal components $\left(\mathrm{PC}_{1}-\mathrm{PC}_{10}\right),\left(\mathrm{Q}_{1}-\mathrm{Q}_{10}\right)+\mathrm{K}$, and $\left(\mathrm{PC}_{1}-\right.$ $\left.\mathrm{PC}_{10}\right)+\mathrm{K}$, and coefficient of parentage as a random factor in combination with the $\mathrm{PC}$ and $\mathrm{Q}$ matrix and observing the Q-Q plots of $P$-values. Manhattan plots were created using the 'qqman' package in $\mathrm{R}^{[52]}$. Once the MTAs were identified, comparisons were made between the traits and also with previously detected MTAs in the WAMI population $^{[30-32]}$.

\section{Results}

\subsection{Phenotypic variation and broad-sense heritability}

Agronomic traits showed a substantial reduction in trait values under HS compared to YP. GY, TGW, and GN decreased by $31 \%, 17 \%$, and $17 \%$, respectively. The length of the growth cycle also decreased under HS compared to YP, where the average DTH and DTM were shortened by 14 and 38 days, respectively. $\mathrm{PH}$ reduced by $16 \mathrm{~cm}$ on population average under HS (Table S1). Similar to the results found with agronomic traits, the values of the SRIs decreased in HS compared to YP, while the water indices (WI, NWI_1, NWI_2, NWI_3, and NWI_4), TCARI (transformed chlorophyll absorption in reflectance index), $\mathrm{AB}$ ratio (Chlorophyll ratio), ARI1 (anthocyanin reflectance index 1), ARI2, and NDPI (normalized difference pigment index) increased under $\mathrm{HS}$, compared to YP (Table 2).

Under YP, the SRIs related to light use efficiency (e.g., PRI, SIPI2 (structure insensitive pigment index 2)) showed an increasing trend from booting to late heading (H7), whereas SRIs related to vegetation (SR, NDVI_670, NDVI_705, and MTCI1 (MERIS terrestrial chlorophyll index 1)) and water status (WI, NWI_1, NWI_2, NWI_3, and NWI_4) showed a decreasing trend during the same period. Under HS, the SRIs related to chlorophyll (RARSa (ratio analysis of reflectance spectra for chlorophyll a), RARSb, ARI1, and ARI2) and carotenoid (NDPI and PSRI (plant senescence reflectance index)) content increased from booting to the heading stage, and SRIs related to vegetation (SR, NDVI_670, NDVI_705, EVI (enhanced vegetation index), MTCI1, OSĀVI (optimized soil adjusted vegetation index), and TCARI) decreased during the same period, while indices related to water status (WI, NWI_1, and NWI_4) did not change much between the two stages. Most of the SRIs had similar trends under YP and HS, while TCARI, PRI, NWI_2, NWI_3, and RARSb showed contrasting patterns between the two environments.

The highest $H^{2}$ for most of the SRIs were observed at the heading stage under YP. Under HS, moderate to high $H^{2}$ was observed at both booting and heading stage (Table 2).

\subsection{Correlations}

Under YP, half of the studied SRIs showed significant correlations with GY at booting and heading, whereas only four SRIs showed good correlations at late heading $(P<0.01$, Table 2). EVI, OSAVI, and ARI1 were correlated with GY across the three measured stages. Under HS, eight and 19 SRIs were correlated significantly with GY at booting and heading stage, respectively. NDVI_705, MTCI1, WI, NWI_1, NWI_2, NWI_3, NWI_ 4, and PRI were correlated with GY at both stages.

Significant correlations between the SRIs were observed in both YP and HS environments (Table S2). Most of the high correlations were observed in the same SRIs group (e.g., NDVI_670, and NDVI_705; WI, NWI_1, NWI_2, NWI_3, and NWI_4), while some strong correlations were found between SRIs from different groups (e.g., SR with RARSc; SIPI2 with NDVI_670; and PRI with NDQI).

\subsection{Efficient SRIs for indirect selection of GY}

According to the heritability estimates and correlations, several efficient SRIs were identified as indirect indices for GY at different growth stages: under YP, EVI was an efficient selection index from booting until late heading stage; NDPI, NPQI (normalized phaeophytinization index), PRI, ARI2, MTCI4, and NWI_1 were efficient SRIs at both booting and heading stages; NDVI_705 was efficient at booting stage; CRI2 (carotenoid reflectance index 2) was efficient from heading to late heading; while ARI1 and OSAVI were more efficient after heading (Fig. 1(a)). Under HS, NDVI_705 and PRI were efficient in predicting GY at both booting and heading stages; while NW1_2 was efficient only at the booting stage, and RARS $\bar{S}$, ARI2, AB ratio, PSSRa (pigment specific simple ratio a), MTCI2, and WI were efficient at the heading stage (Fig. 1(b)). NDVI_705 and PRI were common efficient SRIs for YP and $\mathrm{HS}$, while RARSb, AB ratio, PSSRa, and WI were specific SRIs for HS. 
Table 2 Mean values, broad sense heritability $\left(H^{2}\right)$, and correlation coefficients $(r)$ of SRIs with GY of the WAMI population under YP and HS environments in Ciudad Obregon, Mexico during the 2015-2016 growing season

\begin{tabular}{|c|c|c|c|c|c|c|c|c|c|c|c|c|c|c|c|}
\hline \multirow{3}{*}{ SRIs } & \multicolumn{9}{|c|}{ YP } & \multicolumn{6}{|c|}{ HS } \\
\hline & \multicolumn{3}{|c|}{ Booting } & \multicolumn{3}{|c|}{ Heading } & \multicolumn{3}{|c|}{ Heading +7 days } & \multicolumn{3}{|c|}{ Booting } & \multicolumn{3}{|c|}{ Heading } \\
\hline & Mean & $H^{2}$ & $r$ & Mean & $H^{2}$ & $r$ & Mean & $H^{2}$ & $r$ & Mean & $H^{2}$ & $r$ & Mean & $H^{2}$ & $r$ \\
\hline SR & 25.84 & 0.45 & 0.01 & 23.06 & 0.63 & -0.11 & 16.86 & 0.11 & -0.02 & 19.83 & 0.68 & 0.18 & 14.39 & 0.77 & $0.29 * *$ \\
\hline NDVI_670 & 0.92 & 0.07 & 0.13 & 0.91 & 0.70 & -0.11 & 0.89 & 0.47 & 0.06 & 0.90 & 0.71 & 0.18 & 0.87 & 0.78 & $0.30 * *$ \\
\hline NDVI_705 & 0.74 & 0.32 & $0.25 * *$ & 0.73 & 0.54 & 0.09 & 0.70 & 0.34 & 0.19 & 0.66 & 0.69 & $0.26^{* *}$ & 0.65 & 0.74 & $0.39 * *$ \\
\hline EVI & 0.66 & 0.26 & $0.23 * *$ & 0.68 & 0.58 & $0.15^{* *}$ & 0.61 & 0.34 & $0.23 * *$ & 0.65 & 0.77 & 0.14 & 0.58 & 0.64 & 0.21 \\
\hline MTCI1 & 3.67 & 0.52 & 0.18 & 3.55 & 0.54 & 0.04 & 2.91 & 0.02 & 0.09 & 2.56 & 0.67 & $0.24 * *$ & 2.36 & 0.73 & $0.38^{* *}$ \\
\hline MTCI2 & 0.23 & 0.52 & $0.36^{* *}$ & 0.27 & 0.45 & $0.26 * *$ & 0.28 & 0.21 & 0.21 & 0.19 & 0.72 & 0.08 & 0.25 & 0.73 & $0.22 * *$ \\
\hline OSAVI & 0.70 & 0.07 & $0.28 * *$ & 0.71 & 0.54 & $0.22 * *$ & 0.68 & 0.40 & $0.30 * *$ & 0.70 & 0.77 & 0.14 & 0.67 & 0.63 & 0.21 \\
\hline TCARI & 0.08 & 0.50 & -0.08 & 0.08 & 0.54 & -0.03 & 0.10 & 0.04 & 0.07 & 0.13 & 0.84 & -0.08 & 0.10 & 0.48 & -0.19 \\
\hline WI & 0.86 & 0.21 & $-0.23 * *$ & 0.84 & 0.48 & $-0.22 * *$ & 0.80 & 0.04 & -0.13 & 0.88 & 0.54 & $-0.30 * *$ & 0.88 & 0.63 & $-0.42 * *$ \\
\hline NWI_1 & -0.08 & 0.22 & $-0.23 * *$ & -0.09 & 0.49 & $-0.22 * *$ & -0.09 & 0.01 & -0.12 & -0.07 & 0.54 & $-0.30 * *$ & -0.07 & 0.63 & $-0.42 * *$ \\
\hline NWI_2 & -0.07 & 0.07 & $-0.22 * *$ & -0.08 & 0.46 & $-0.24 * *$ & -0.08 & 0.03 & -0.08 & -0.06 & 0.63 & $-0.34 * *$ & -0.05 & 0.58 & $-0.43 * *$ \\
\hline NWI_3 & -0.07 & 0.09 & $-0.23 * *$ & -0.09 & 0.48 & $-0.24 * *$ & -0.09 & 0.06 & -0.07 & -0.07 & 0.52 & $-0.30 * *$ & -0.06 & 0.57 & $-0.42 * *$ \\
\hline NWI_4 & -0.07 & 0.22 & $-0.22 * *$ & -0.08 & 0.50 & -0.21 & -0.08 & 0.08 & -0.08 & -0.06 & 0.55 & $-0.30 * *$ & -0.06 & 0.62 & $-0.41 * *$ \\
\hline $\mathrm{AB}$ ratio & 0.02 & 0.45 & 0.02 & 0.03 & 0.68 & 0.20 & 0.06 & 0.01 & 0.08 & 0.03 & 0.69 & -0.16 & 0.04 & 0.52 & $-0.28 * *$ \\
\hline PSSRa & 25.42 & 0.45 & 0.21 & 22.87 & 0.62 & $0.30 * *$ & 17.11 & 0.11 & 0.17 & 20.10 & 0.68 & -0.01 & 14.67 & 0.78 & -0.07 \\
\hline RARSa & 0.45 & 0.43 & 0.06 & 0.49 & 0.85 & -0.09 & 0.52 & 0.22 & -0.09 & 0.39 & 0.87 & 0.11 & 0.51 & 0.87 & $0.22 * *$ \\
\hline RARSb & 20.59 & 0.58 & -0.05 & 18.30 & 0.59 & -0.15 & 16.23 & 0.03 & -0.06 & 13.02 & 0.75 & 0.15 & 13.63 & 0.43 & $0.22 * *$ \\
\hline RARSc & 21.51 & 0.51 & 0.02 & 19.77 & 0.74 & -0.11 & 15.77 & 0.18 & -0.01 & 16.85 & 0.63 & 0.16 & 13.91 & 0.76 & $0.29 * *$ \\
\hline ARI1 & -0.81 & 0.38 & $-0.35 * *$ & -0.43 & 0.71 & $-0.22 * *$ & 0.34 & 0.56 & $-0.23 * *$ & -0.34 & 0.80 & -0.18 & 0.34 & 0.75 & -0.21 \\
\hline ARI2 & -0.41 & 0.50 & $-0.39 * *$ & -0.24 & 0.76 & $-0.26^{* *}$ & 0.17 & 0.49 & -0.18 & -0.19 & 0.78 & -0.18 & 0.16 & 0.76 & $-0.22 * *$ \\
\hline CRI1 & 19.26 & 0.55 & -0.16 & 14.70 & 0.80 & $-0.24 * *$ & 13.39 & 0.41 & -0.21 & 14.96 & 0.65 & 0.05 & 10.86 & 0.66 & 0.12 \\
\hline CRI2 & 18.45 & 0.59 & -0.18 & 14.26 & 0.83 & $-0.25^{* *}$ & 13.70 & 0.47 & $-0.23 * *$ & 14.63 & 0.68 & 0.01 & 11.20 & 0.66 & 0.06 \\
\hline NPQI & -0.07 & 0.56 & $0.33 * *$ & -0.04 & 0.56 & $0.32 * *$ & -0.02 & 0.02 & 0.09 & -0.09 & 0.62 & 0.02 & -0.06 & 0.45 & 0.03 \\
\hline NDPI & -0.01 & 0.51 & $-0.42 * *$ & 0.01 & 0.82 & $-0.30 * *$ & 0.10 & 0.12 & -0.02 & 0.02 & 0.82 & -0.15 & 0.04 & 0.78 & -0.21 \\
\hline PSRI & -0.005 & 0.04 & -0.21 & -0.005 & 0.86 & -0.21 & 0.03 & 0.01 & 0.07 & -0.01 & 0.83 & -0.13 & -0.001 & 0.81 & -0.21 \\
\hline SIPI2 & 0.92 & 0.21 & 0.07 & 0.91 & 0.74 & -0.15 & 0.90 & 0.49 & 0.01 & 0.90 & 0.67 & 0.15 & 0.88 & 0.76 & $0.27 * *$ \\
\hline PRI & 0.01 & 0.24 & $0.32 * *$ & 0.01 & 0.53 & $0.24 * *$ & 0.03 & 0.04 & 0.08 & 0.01 & 0.83 & $0.29 * *$ & 0.001 & 0.80 & $0.30^{* *}$ \\
\hline
\end{tabular}

Note: SRIs, spectral reflectance indices; GY, grain yield; WAMI, wheat association mapping initiative; YP, yield potential; HS, heat stress; SR, simple ratio; NDVI, normalized difference vegetation index; EVI, enhanced vegetation index; MTCI, MERIS terrestrial chlorophyll index; OSAVI, optimized soil adjusted vegetation index; TCARI, transformed chlorophyll absorption in reflectance index; WI, water index; NWI, normalized water index; AB ratio, chlorophyll ratio; PSSR, pigment specific simple ratio; RARS, ratio analysis of reflectance spectra for chlorophyll; ARI, anthocyanin reflectance index; CRI, carotenoid reflectance index; NPQI, normalized phaeophytinization index; NDPI, normalized difference pigment index; PSRI, plant senescence reflectance index; SIPI, structure insensitive pigment index; PRI, photochemical reflectance index; $* *$, significant at $P<0.01$.

3.4 Marker-trait associations for agronomic traits and efficient SRIs

For agronomic traits, significant SNPs associated with GY were located on chromosome $6 \mathrm{~A}$ under $\mathrm{YP}$, and on $2 \mathrm{~B}$ and $3 \mathrm{~A}$ under HS. SNPs associated with TGW were on 2B (YP) and 6A (HS), and with GN were on 1B (YP), 3A (YP), 1D (HS), and 6D (HS). For DTH, significant SNPs were on 1B, 2A, and 2B under YP, while under HS were located on $5 \mathrm{~A}$ and $6 \mathrm{D}$. Significant markers associated with DTM were on $2 \mathrm{~A}, 3 \mathrm{D}$, and $5 \mathrm{D}$ for $\mathrm{YP}$, and on $1 \mathrm{~A}, 2 \mathrm{~B}$, and 4B for HS. For PH, associated markers were on $3 \mathrm{~B}$ and $3 \mathrm{D}$ under YP, while on 5A and 6A under HS (Table S3).

For efficient SRIs, 280 SNPs located on chromosomes $1 \mathrm{~A}, 1 \mathrm{~B}, 2 \mathrm{~A}, 2 \mathrm{D}, 3 \mathrm{~A}, 3 \mathrm{~B}, 4 \mathrm{~A}, 4 \mathrm{~B}, 5 \mathrm{~A}, 5 \mathrm{~B}, 6 \mathrm{~A}, 6 \mathrm{~B}, 6 \mathrm{D}, 7 \mathrm{~A}$, and $7 \mathrm{~B}$ were identified under YP (Table S3). The largest number of associations were observed for NDPI at the booting stage (83 MTAs, Fig. 2(a)), followed by ARI2 (51 MTAs). Under HS, 43 markers located on chromosomes $1 \mathrm{~A}, 1 \mathrm{~B}, 2 \mathrm{~A}, 2 \mathrm{~B}, 3 \mathrm{~A}, 3 \mathrm{~B}, 4 \mathrm{~A}, 5 \mathrm{~A}, 5 \mathrm{D}, 6 \mathrm{~A}, 6 \mathrm{~B}, 7 \mathrm{~A}, 8 \mathrm{~B}$, and 7D were identified for SRIs. The largest number of associations were observed for NWI_2 at the booting stage (9 MTAs, Fig. 2(h)), followed by ARI2 at the heading stage (6 MTAs). 
(a)

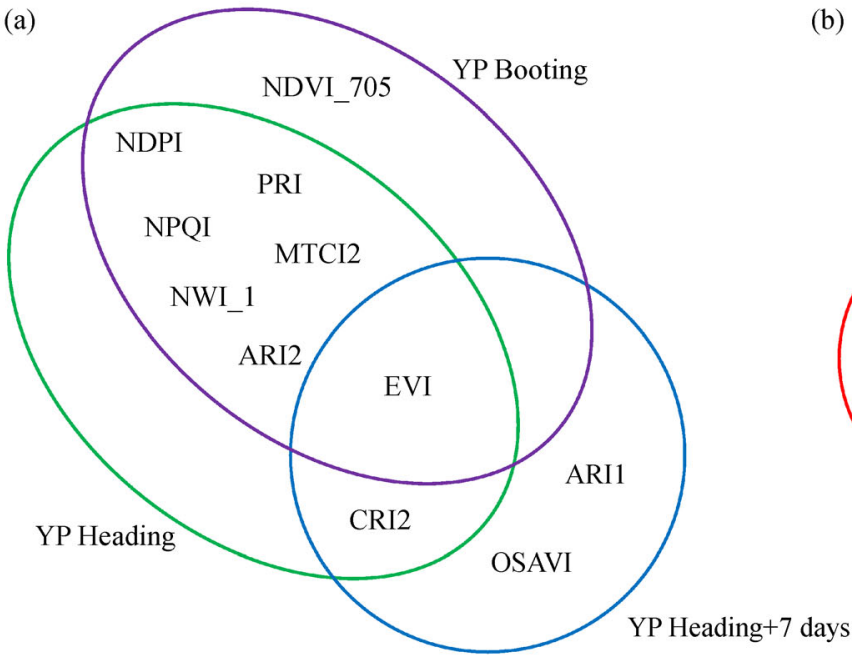

(b)

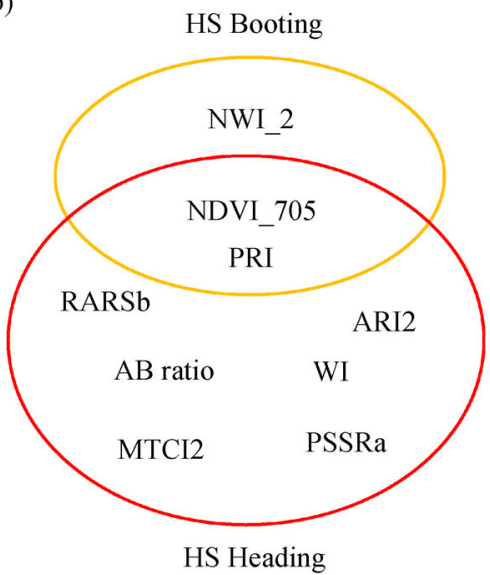

Fig. 1 Common and different spectral reflectance indices (SRIs) showed significant correlations with grain yield (GY) when measured at booting, heading, and heading plus 7 days stages under yield potential (YP) (a) and heat stress (HS) (b) environments in Cd. Obregon, Mexico during the 2015-2016 season. NDPI, normalized difference pigment index; PRI, photochemical reflectance index; NPQI, normalized phaeophytinization index; MTCI, MERIS terrestrial chlorophyll index; NWI, normalized water index; ARI, anthocyanin reflectance index; EVI, enhanced vegetation index; NDVI, normalized difference vegetation index; CRI, carotenoid reflectance index; OSAVI, optimized soil adjusted vegetation index; RARS, ratio analysis of reflectance spectra for chlorophyll; AB ratio, chlorophyll ratio; WI, water index; PSSR, pigment specific simple ratio.

\subsection{Common genomic regions and markers for multiple} traits

Most of the significant markers associated with efficient SRIs were clustered on 12 chromosomes: 1B, 2A, 3B, 4A, 4B, 5A, 5B, 6A, 6B, 7A, 7D, and especially $3 \mathrm{~A}$. Fourteen genomic regions on $1 \mathrm{~B}(60-62 \mathrm{cM}), 3 \mathrm{~A}(15,85-90,101-$ $105 \mathrm{cM}), 3 \mathrm{~B}(132-134 \mathrm{cM}), 4 \mathrm{~A}(47-51 \mathrm{cM}), 4 \mathrm{~B}(71-$ $75 \mathrm{cM}), 5 \mathrm{~A}(43-49,56-60,89-93 \mathrm{cM}), 5 \mathrm{~B}(124-125 \mathrm{cM})$, $6 \mathrm{~A}(80-85 \mathrm{cM})$, and $6 \mathrm{~B}(57-59,71 \mathrm{cM})$ were associated with multiple SRIs (Fig. 3). For example, the locus on $3 \mathrm{~A}$ at $88-90 \mathrm{cM}$ was associated with NDPI, ARI2 and PRI under YP. Among the markers in this region, 35 markers were common between NDPI and ARI2, three markers were common between NDPI and PRI, and one SNP (Kukri_c25564_185) was associated with NDPI, ARI2 and PRI (Table 3). The locus on $3 \mathrm{~A}$ at $101-105 \mathrm{cM}$ (612$618 \mathrm{Mb}$ on physical map) was associated with NDPI, ARI2, and CRI2 under YP. Among the markers in this region, wsnp_Ex_c26887_36107413 was associated with ARI2 and CRI2, and BS00056089_51 was associated with NDPI, ARI2, and CRI2. Three markers on 4B at $71 \mathrm{cM}$ (c. $548 \mathrm{Mb}$ on the physical map) was associated with EVI and OSAVI. Four markers on 6B at $71 \mathrm{cM}$ (c. $526 \mathrm{Mb}$ on the physical map) was associated with NDVI_705 and AB ratio (Table 3).

On chromosome 6A, a region at $80-85 \mathrm{cM}$ was associated with GY and PRI under YP, and with TGW, PH, and NWI 2 under HS. At the Vrn-1 locus on 5A at 89$93 \mathrm{cM}, \mathrm{DTH}, \mathrm{PH}, \mathrm{ARI} 2$ and PRI under HS were co-located (Fig. 3).
3.6 Comparison with the previously identified marker-trait associations on the WAMI population

The WAMI population has been widely used for association mapping studies. In the present study, the locus in chromosome $1 \mathrm{~B}$ at $70 \mathrm{cM}$ for GN was previously reported for peduncle length ${ }^{[31]}$ and spike ethylene ${ }^{[53]}$ (Table S4). The other locus in chromosome 1B at $148 \mathrm{cM}$ for $\mathrm{PH}$ was earlier reported for harvest index and $\mathrm{TGW}^{[31,54]}$. The locus in 2A (143 cM) for EVI was co-located QTL for $\mathrm{TGW}^{[54]}$. The locus on $3 \mathrm{~B}(61 \mathrm{cM})$ for $\mathrm{PH}$ was earlier identified for SPAD at the grain-filling stage ${ }^{[31]}$. On 4B, the locus at $66 \mathrm{cM}$ for DTM has been reported for $\mathrm{GY}^{[54]}$, and the locus at $71 \mathrm{cM}$ for EVI and OSAVI was reported for spike dry weight ${ }^{[53]}$. On $5 \mathrm{~A}$, the locus at $60 \mathrm{cM}$ for PRI was previously reported for $\mathrm{TGW}^{[54]}$, while the locus at $90 \mathrm{cM}$ was reported for DTH and flowering time $\mathrm{e}^{[1,30,31]}$ and was identified as the Vrn-1 locus. On 6A, the locus at $80 \mathrm{cM}$ for TGW was reported to co-located with QTL for $\mathrm{PH}^{[31]}$, and the locus at $85 \mathrm{cM}$ for GY was reported for GY, biomass, TGW, and SPAD at grain-filling ${ }^{[31,54]}$. The locus on $7 \mathrm{~A}(35 \mathrm{cM})$ for NPQI was previously identified for $\mathrm{GY}^{[54]}$.

\section{Discussion}

Identification of indirect selection indices for GY in target environments is important in wheat breeding programs with large sets of germplasm and genotypes. An efficient indirect index should be significantly correlated with GY, 

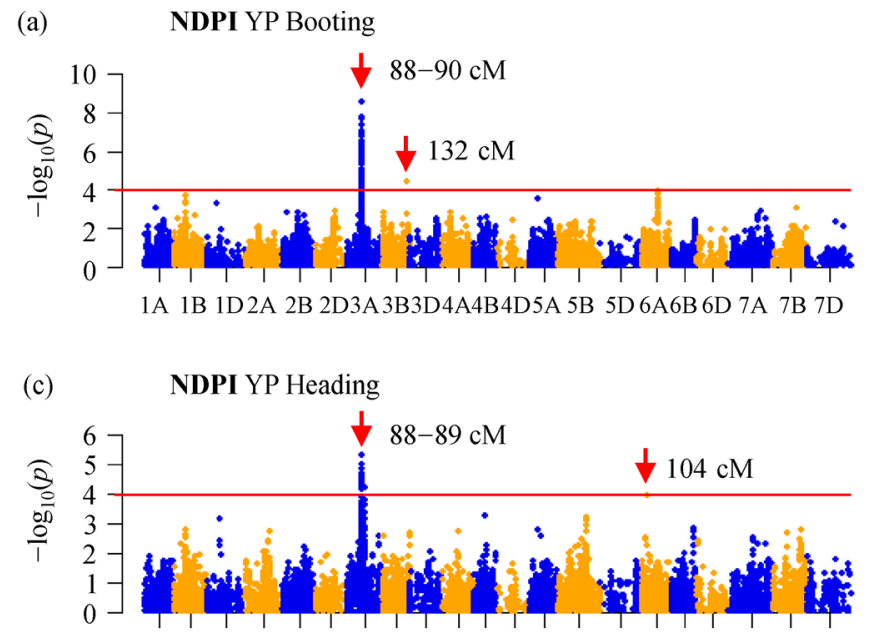

1A 1B 1D2A 2B 2D3A3B3D4A4B4D5A 5B 5D 6A6B6D 7A 7B 7D
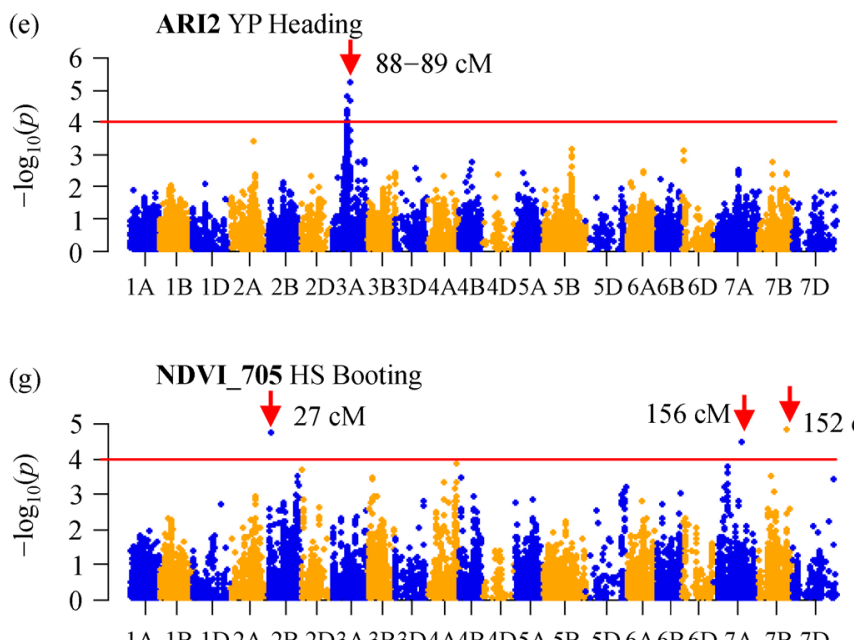

1A 1B 1D2A 2B 2D3A3B3D4A4B4D5A 5B 5D 6A6B6D 7A 7B 7D

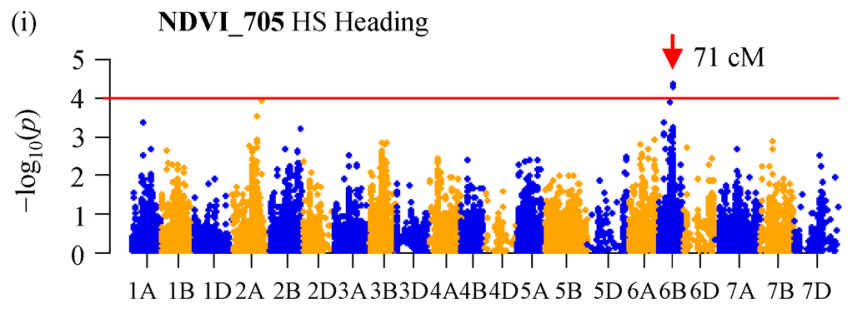

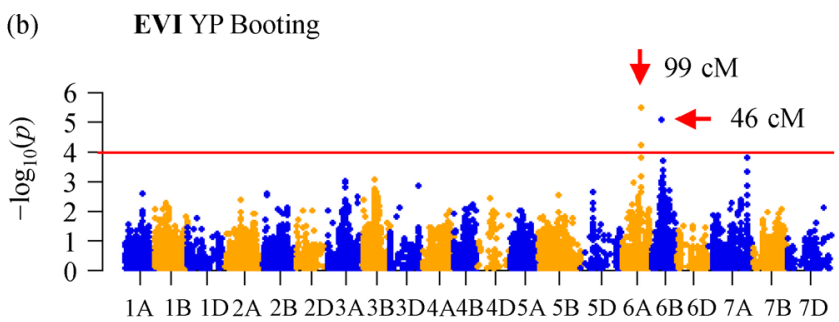
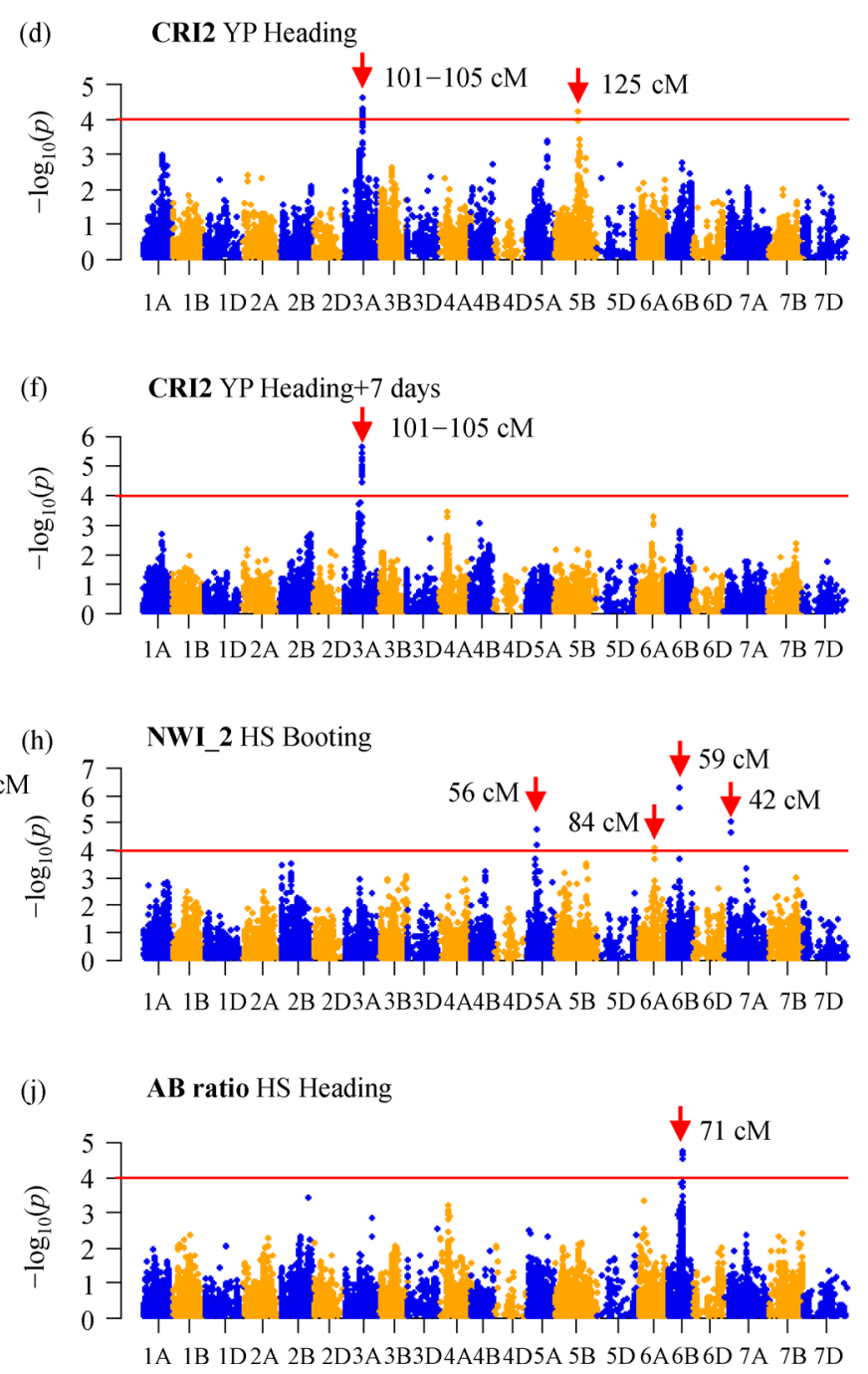

Fig. 2 Manhattan plots for spectral reflectance indices (SRIs) of wheat association mapping initiative (WAMI) population at booting, heading, and heading plus 7 days under yield potential (YP) ((a)-(f)) and heat stress (HS) ((g)-(j)) environments. NDPI, normalized difference pigment index; EVI, enhanced vegetation index; CRI, carotenoid reflectance index; ARI, anthocyanin reflectance index; NDVI, normalized difference vegetation index; NWI, normalized water index; AB ratio, chlorophyll ratio.

showing high heritability and genetic variability ${ }^{[55]}$. In the case of physiological traits, the phenological stage at which the measurements are taken also may affect the ability to predict GY. In the current study, most SRIs were associated with GY at booting and heading stages under YP, but high heritability estimates of SRIs was observed at the heading stage. Under HS, significant correlations and high heritability of SRIs were observed at both booting and heading stages. These results suggest that the heading stage could be the most optimum stage to conduct the measurement of SRIs for early selection/prediction of GY under both conditions. Similar observations were also reported in irrigated spring wheat ${ }^{[23,56]}$ and durum wheat ${ }^{[57,58]}$. In addition, we also identified several efficient SRIs at booting and late heading stages, which could be used for phenotyping large populations. 

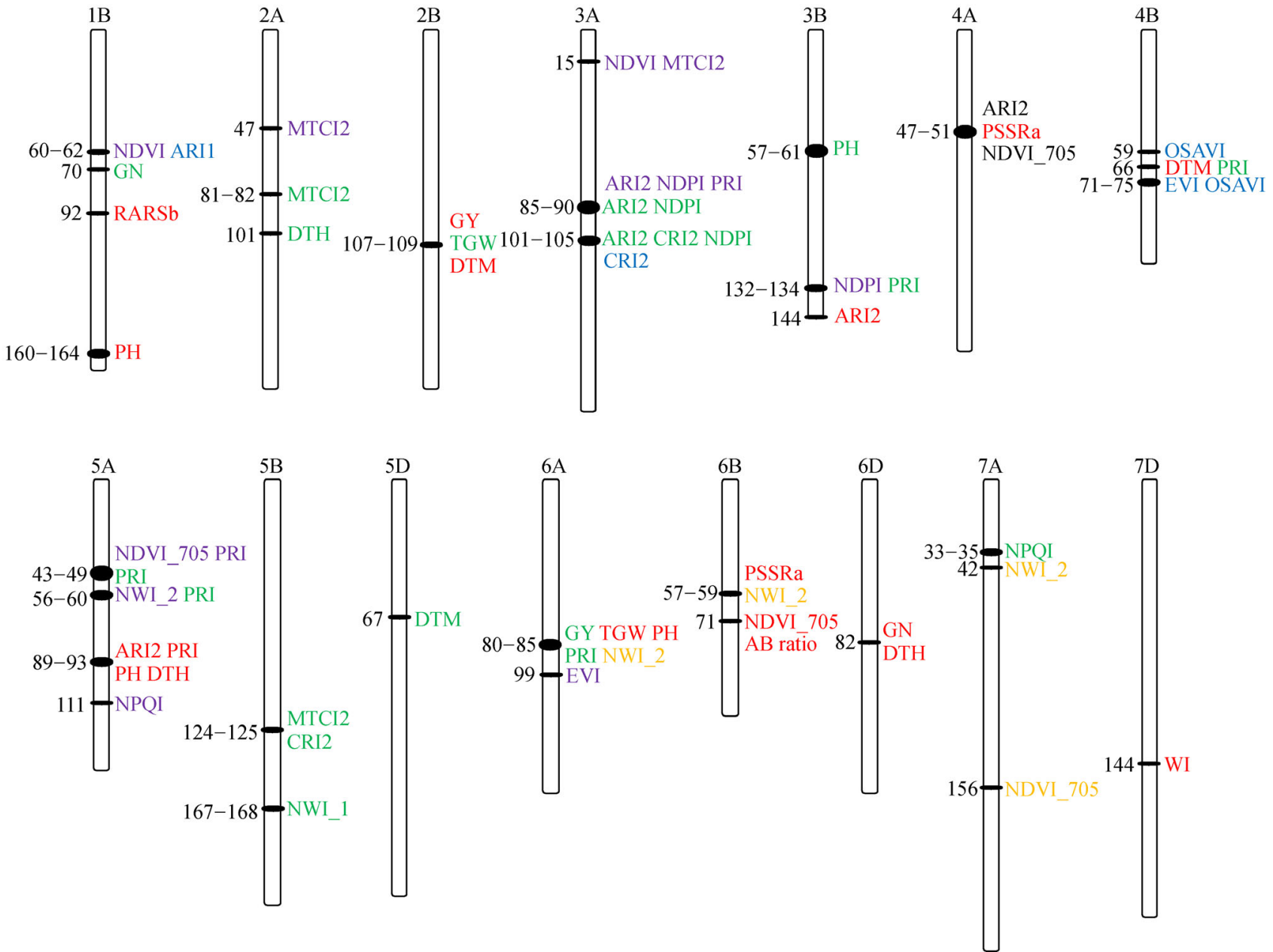

Fig. 3 Genomic regions associated with agronomic traits and spectral reflectance indices (SRIs) in the wheat association mapping initiative (WAMI) population at booting (purple), heading (green), and heading plus 7 days (blue) under yield potential (YP) and at booting (orange) and heading (red) stages under heat stress (HS) environments. NDVI, normalized difference vegetation index; ARI, anthocyanin reflectance index; GN, grain number; RARS, ratio analysis of reflectance spectra for chlorophyll; PH, plant height; MTCI, MERIS terrestrial chlorophyll index; DTH, days to heading; GY, grain yield; TGW, thousand-grain weight; DTM, days to maturity; NDPI, normalized difference pigment index; PRI, photochemical reflectance index; CRI, carotenoid reflectance index; PSSR, pigment specific simple ratio; OSAVI, optimized soil adjusted vegetation index; EVI, enhanced vegetation index; NWI, normalized water index; NPQI, normalized phaeophytinization index; AB ratio, chlorophyll ratio; WI, water index.

In the present study, common efficient SRIs such as NDVI 705, PRI, and ARI2 were identified for both YP and $\mathrm{HS}$ conditions, highlighting their values as proxies for GY. The water indices (WI and NWI) also showed significant correlations with GY under YP and HS conditions. The water-based indices estimate water content of the canopy, and the higher associations between these indices and GY indicated that canopy water content plays a vital role in the productivity of a given genotype. Similar results were observed by Prasad et al. ${ }^{[56]}$ under rain-fed conditions. Further, the simple ratio index (WI) and normalized indices (NWI_1, NWI_2, NWI_3, and NWI 4) of water status showed similar predictive ability for $\overline{G Y}$ in this study, confirming the findings in previous studies of spring wheat ${ }^{[12,23,56]}$.
To the best of our knowledge, this is the first study to report genomic regions associated with SRIs under HS. Recently, Gizaw et al. ${ }^{[27,28]}$ identified the genomic regions for SRIs through GWAS in fully irrigated, rainfed, and drought-stressed environments in wheat. They reported that under irrigation, QTLs for NDVI were located on chromosome $3 \mathrm{~A}, 3 \mathrm{~B}, 4 \mathrm{~A}, 5 \mathrm{~A}, 5 \mathrm{~B}, 7 \mathrm{~A}$, and $7 \mathrm{~B}$ in winter wheat, and on $2 \mathrm{~B}, 3 \mathrm{~B}, 4 \mathrm{~B}, 4 \mathrm{D}, 5 \mathrm{~B}$, and $7 \mathrm{~A}$ in spring wheat. In contrast, in this study, we identified QTLs for NDVI 705 on 1B, 3A, and 5A, which were far away from the QTLs reported by Gizaw et al. ${ }^{[27,28]}$. The QTLs for NWI_1 under irrigation were reported on $6 \mathrm{~A}, 6 \mathrm{~B}^{[28]}$, and $2 \mathrm{~A}, 5 \mathrm{~A}, 5 \mathrm{~B}^{[27]}$ in winter and spring wheat, respectively; while QTLs for NWI 1 were located at a different locus on $5 \mathrm{~B}$ in this study. Previously QTLs for 
Table 3 Significant $(P<0.0001)$ markers associated with multiple spectral reflectance indices of the WAMI population at booting (YPB), heading (YPH), and 7 days after heading (YPH7) under YP, and at booting (HSB), heading (HSH) under HS in Ciudad Obregon, Mexico during the 20152016 growing season

\begin{tabular}{|c|c|c|c|}
\hline Marker & Chromosome & Position/cM & Associated traits \\
\hline BS00075119_51 & $3 \mathrm{~A}$ & 15 & NDVI_705 (YPB), MTCI2 (YPB) \\
\hline BobWhite_c9468_453 & $3 \mathrm{~A}$ & 88 & NDPI (YPB, YPH), ARI2 (YPB, YPH) \\
\hline BobWhite_c9468_478 & $3 \mathrm{~A}$ & 88 & NDPI (YPB, YPH), ARI2 (YPB, YPH) \\
\hline BS00070511_51 & $3 \mathrm{~A}$ & 88 & NDPI (YPB), ARI2 (YPB) \\
\hline IAAV1334 & $3 \mathrm{~A}$ & 88 & NDPI (YPB), ARI2 (YPB) \\
\hline TA001068-0306-w & $3 \mathrm{~A}$ & 88 & NDPI (YPB, YPH), ARI2 (YPB, YPH) \\
\hline wsnp_BE406587A_Ta_2_1 & $3 \mathrm{~A}$ & 88 & NDPI (YPB, YPH), ARI2 (YPB, YPH) \\
\hline wsnp_Ex_c22766_31972202 & $3 \mathrm{~A}$ & 88 & NDPI (YPB, YPH), ARI2 (YPB, YPH) \\
\hline wsnp_Ex_c24293_33532428 & $3 \mathrm{~A}$ & 88 & NDPI (YPB, YPH), ARI2 (YPB, YPH) \\
\hline wsnp_Ex_c9468_15697512 & $3 \mathrm{~A}$ & 88 & NDPI (YPB, YPH), ARI2 (YPB, YPH) \\
\hline BS00040798_51 & $3 \mathrm{~A}$ & 89 & NDPI (YPB, YPH), ARI2 (YPB) \\
\hline BS00048031_51 & $3 \mathrm{~A}$ & 89 & NDPI (YPB), ARI2 (YPB) \\
\hline Excalibur_c29205_537 & $3 \mathrm{~A}$ & 89 & NDPI (YPB, YPH), ARI2 (YPB, YPH) \\
\hline Excalibur_c7181_813 & $3 \mathrm{~A}$ & 89 & NDPI (YPB, YPH), ARI2 (YPB) \\
\hline Excalibur_c854_1459 & $3 \mathrm{~A}$ & 89 & NDPI (YPB, YPH), ARI2 (YPB) \\
\hline Excalibur_rep_c76510_255 & $3 \mathrm{~A}$ & 89 & NDPI (YPB, YPH), ARI2 (YPB, YPH) \\
\hline Kukri_c101770_328 & $3 \mathrm{~A}$ & 89 & NDPI (YPB, YPH), ARI2 (YPH) \\
\hline Kukri_c82097_197 & $3 \mathrm{~A}$ & 89 & NDPI (YPB, YPH), ARI2 (YPB) \\
\hline RAC875_c10669_714 & $3 \mathrm{~A}$ & 89 & NDPI (YPB), ARI2 (YPB) \\
\hline wsnp_CAP11_c318_261649 & $3 \mathrm{~A}$ & 89 & NDPI (YPB), ARI2 (YPB) \\
\hline wsnp_Ex_c2331_4369782 & $3 \mathrm{~A}$ & 89 & NDPI (YPB), ARI2 (YPB) \\
\hline wsnp_Ex_c25668_34932560 & $3 \mathrm{~A}$ & 89 & NDPI (YPB), ARI2 (YPB) \\
\hline wsnp_Ex_rep_c66865_65262277 & $3 \mathrm{~A}$ & 89 & NDPI (YPB), ARI2 (YPB) \\
\hline wsnp_Ex_rep_c66865_65262612 & $3 \mathrm{~A}$ & 89 & NDPI (YPB), ARI2 (YPB) \\
\hline wsnp_Ex_rep_c66865_65263145 & $3 \mathrm{~A}$ & 89 & NDPI (YPB), ARI2 (YPB) \\
\hline wsnp_Ra_c10669_17515792 & $3 \mathrm{~A}$ & 89 & NDPI (YPB), ARI2 (YPB) \\
\hline$w s n p \_R a \_c 29280 \_38672141$ & $3 \mathrm{~A}$ & 89 & NDPI (YPB, YPH), ARI2 (YPH) \\
\hline wsnp_RFL_Contig4814_5829093 & $3 \mathrm{~A}$ & 89 & NDPI (YPB, YPH), ARI2 (YPB) \\
\hline BobWhite_c43681_334 & $3 \mathrm{~A}$ & 90 & NDPI (YPB), ARI2 (YPB) \\
\hline BS00110405_51 & $3 \mathrm{~A}$ & 90 & NDPI (YPB), ARI2 (YPB) \\
\hline GENE-3343_183 & $3 \mathrm{~A}$ & 90 & NDPI (YPB), ARI2 (YPB) \\
\hline IAAV8924 & $3 \mathrm{~A}$ & 90 & NDPI (YPB), PRI (YPB) \\
\hline Kukri_c25564_185 & $3 \mathrm{~A}$ & 90 & NDPI (YPB), PRI (YPB), ARI2 (YPB) \\
\hline RAC875_c842_1516 & $3 \mathrm{~A}$ & 90 & NDPI (YPB), ARI2 (YPB) \\
\hline RAC875_rep_c117959_132 & $3 \mathrm{~A}$ & 90 & NDPI (YPB), PRI (YPB) \\
\hline RFL_Contig1034_2351 & $3 \mathrm{~A}$ & 90 & NDPI (YPB), ARI2 (YPB) \\
\hline wsnp_Ex_c35073_43285821 & $3 \mathrm{~A}$ & 90 & NDPI (YPB), PRI (YPB) \\
\hline wsnp_JD_c2743_3678590 & $3 \mathrm{~A}$ & 90 & NDPI (YPB), ARI2 (YPB) \\
\hline wsnp_JD_c3034_4017676 & $3 \mathrm{~A}$ & 90 & NDPI (YPB), ARI2 (YPB) \\
\hline wsnp_Ku_c3286_6111360 & $3 \mathrm{~A}$ & 90 & NDPI (YPB), ARI2 (YPB) \\
\hline BSO0000445_51 & $3 \mathrm{~A}$ & 101 & CRI2 (YPH, YPH7) \\
\hline BSO0001478 51 & $3 \mathrm{~A}$ & 101 & CRI2 (YPH, YPH7) \\
\hline
\end{tabular}


(Continued)

\begin{tabular}{|c|c|c|c|}
\hline Marker & Chromosome & Position/cM & Associated traits \\
\hline BS00061179_51 & $3 \mathrm{~A}$ & 101 & CRI2 (YPH, YPH7) \\
\hline BS00080879_51 & $3 \mathrm{~A}$ & 101 & CRI2 (YPH, YPH7) \\
\hline Excalibur_c39248_485 & $3 \mathrm{~A}$ & 101 & CRI2 (YPH, YPH7) \\
\hline wsnp_Ex_c26887_36107413 & $3 \mathrm{~A}$ & 103 & CRI2 (YPH, YPH7), ARI2 (YPH) \\
\hline BobWhite_c13704_244 & $3 \mathrm{~A}$ & 104 & CRI2 (YPH, YPH7) \\
\hline BS00056089_51 & $3 \mathrm{~A}$ & 104 & NDPI (YPH), ARI2 (YPH), CRI2 (YPH7) \\
\hline RAC875_rep_c109433_782 & $3 \mathrm{~A}$ & 104 & CRI2 (YPH, YPH7) \\
\hline BS00061173_51 & $3 \mathrm{~A}$ & 105 & CRI2 (YPH, YPH7) \\
\hline wsnp_Ex_c9483_15722127 & $3 \mathrm{~A}$ & 105 & CRI2 (YPH, YPH7) \\
\hline RAC875_rep_c72275_185 & 3B & 132 & NDPI (YPB), PRI (YPH) \\
\hline Excalibur_c82684_66 & $4 \mathrm{~B}$ & 71 & EVI (YPH7), OSAVI (YPH7) \\
\hline RAC875_c103110_275 & $4 \mathrm{~B}$ & 71 & EVI (YPH7), OSAVI (YPH7) \\
\hline$R A C 875 \_c 24550 \_1150$ & $4 \mathrm{~B}$ & 71 & EVI (YPH7), OSAVI (YPH7) \\
\hline IACX3657 & $5 \mathrm{~A}$ & 43 & NDVI_705 (YPB), PRI (YPB) \\
\hline RAC875_c13931_205 & $5 \mathrm{~A}$ & 89 & ARI2 (HSH), PRI (HSH) \\
\hline RAC875_rep_c112818_870 & $5 \mathrm{~B}$ & 125 & CRI2 (YPH), MTCI2 (YPH) \\
\hline BobWhite_c13091_385 & $6 \mathrm{~B}$ & 71 & NDVI_705 (HSH), AB ratio (HSH) \\
\hline Ex_c100170_579 & $6 \mathrm{~B}$ & 71 & NDVI_705 (HSH), AB ratio (HSH) \\
\hline Excalibur_rep_c70364_129 & $6 \mathrm{~B}$ & 71 & NDVI_705 (HSH), AB ratio (HSH) \\
\hline IAAV1816 & $6 \mathrm{~B}$ & 71 & NDVI_705 (HSH), AB ratio (HSH) \\
\hline
\end{tabular}

Note: WAMI, wheat association mapping initiative; NDVI, normalized difference vegetation index; MTCI, MERIS terrestrial chlorophyll index; NDPI, normalized difference pigment index; ARI, anthocyanin reflectance index; PRI, photochemical reflectance index; CRI, carotenoid reflectance index; EVI, enhanced vegetation index; OSAVI, optimized soil adjusted vegetation index; $\mathrm{AB}$ ratio, chlorophyll ratio.

PRI were reported on 2A, 3A, 4A, 6B, and 7A in winter wheat under irrigation ${ }^{[28]}$, while in this study, QTLs for PRI were identified on $3 \mathrm{~B}, 4 \mathrm{~B}, 5 \mathrm{~A}$, and $6 \mathrm{~A}$. Also, the marker wsnp_Ex_c8884_14841846 (3A, $105 \mathrm{cM})$ accociated with $\overline{C R} \mathrm{2} 2$ under $\overline{\mathrm{YP}}$ in this study was reported to associate with PRI under drought, rainfed, and irrigation conditions $^{[28]}$. The markers wsnp_Ex_c22727_31934296 and wsnp_Ex_c7729_13177883 (5A, $89-91 \mathrm{cM})$ for DTH in this study were previously reported associated with SR and NDVI ${ }^{[28]}$. Among the SRIs, NDVI is the most used and consistent index for in-season selection and yield prediction $^{[25,26]}$. The QTLs for NDVI 705 on 1B (60-62 $\mathrm{cM})$ under YP and on $2 \mathrm{~B}(27 \mathrm{cM})$ and $6 \mathrm{~B}(71 \mathrm{cM})$ under HS were very close to the reported loci in durum wheat under drought stress ${ }^{[59]}$. The locus for NDVI 705 on 7B $(152 \mathrm{cM})$ under HS was about $10 \mathrm{cM}$ away from a NDVI QTL detected in a bi-parental population under heat ${ }^{[60]}$. Our study identified several genomic regions for SRIs under YP and HS, while few common loci for both environments were observed. These observations again confirmed that different stresses on crops at the same time, or at different times during the same growing season, may produce different metabolic and physiological responses ${ }^{[61]}$

The WAMI population was widely used for GWAS studies, and some loci identified in our analysis were located closely to previously reported QTLs for GY and yield components in the same population. For example, the locus on chromosome 1B for NDVI and ARI2 was $2 \mathrm{cM}$ away from the adaptation to density locus (at $64 \mathrm{cM})^{[32]}$; the locus on 2A for EVI was co-located with that for $\mathrm{TGW}^{[54]}$; the locus on $4 \mathrm{~B}$ for EVI and OSAVI was reported for spike dry weight ${ }^{[53]}$; the locus on $5 \mathrm{~A}$ for PRI was previously reported for $\mathrm{TGW}^{[54]}$; the locus on chromosome 6A for PRI and NWI_2 was previously reported to be associated with GY, biomass, $\mathrm{PH}$, and chlorophyll content under irrigated YP conditions ${ }^{[31]}$; and the locus on 7A for NPQI was previously identified for $\mathrm{GY}^{[54]}$. Also, the locus for ARI2 and PRI was co-located with DTH and PH on the Vrn-1 locus on 5A, verifying the common sense assumption that major developmental genes modulate key physiological processes.

BLAST results of the significant markers associated with multiple SRIs indicated that most of the candidate genes were related to transportation, metabolism, senescence, and abiotic and biotic resistance in plants (Table S3). For example, a transmembrane protein gene (TraesCS5A01G052100.1) was associated with NDVI 705 and PRI. The senescence-associated family protein (DUF581) gene (TraesCS3A01G289000.1) 
associated with NDPI and ARI2, was a FCS-Like Zinc finger gene regulated by sugars, cellular energy level, and abiotic stress ${ }^{[62]}$. A gene coding ABC transporter B family protein (TraesCS3A01G285200.1) was also associated with NDPI and ARI2, and this protein is a powerful transporter driving the exchange of compounds across biological membranes ${ }^{[63]}$. A blue copper protein gene (TraesCS4B01G271800.1) associated with EVI and OSAVI, can shuttle electrons from a protein acting as an electron donor to another acting as an electron acceptor in photosynthesis $^{[64]}$. A Myb transcription factor gene (TraesCS3A01G367600.1) associated with NDPI, ARI2, and CRI2 was involved in controlling various processes, such as responses to biotic and abiotic stresses, development, differentiation, metabolism, and defense in plants $^{[65]}$. A candidate gene (TraesCS3A01G009200.1) associated with NDVI_705 and MCI2 was characterized as a disease resistance gene encoding the NBS-LRR-like resistance protein ${ }^{[66]}$.

Although our measurements cover phenological stages that are highly relevant for adaptation to stress conditions, further measurements of SRIs after anthesis would be needed to fully understand their relationships with yield. Nevertheless, our results have great potential value since the SRIs reported here were analyzed in elite populations under HS and in terms of their genomic regions for the first time. Further research supporting these findings in similar environments using different germplasm will help to reinforce our results. Analysis of the same genomic regions under different severity of HS will provide useful data for breeders and physiologists to help underpin the genomic bases of the traits. Additionally, the exploration of these traits under drought conditions, or combined heat and drought conditions would enable the identification of commonalities between different stresses.

\section{Conclusions}

Spectral reflectance indices are valuable tools to screen agronomic and physiological traits in large populations. In this study, we identified EVI as the SRI that was correlated with GY under YP condition at the booting, heading, and heading plus 7 days stages. PRI and NDVI were efficient under HS at booting and heading stages. Several SRIs showed high heritability estimates and marker-trait associations were identified for them. This information can be further used in developing molecular markers for selecting high yielding lines under YP and HS conditions.

Supplementary materials The online version of this article at https://doi.org/10.15302/J-FASE-2019269 contains supplementary materials (Tables S1-S4).

Acknowledgements This work was implemented by the CIMMYT as part of the projects ARCADIA and MasAgro Trigo in collaboration with the CIMMYT, made possible by the generous support of SAGARPA MasAgro
Trigo and ARCADIA. Any opinions, findings, conclusions, or recommendations expressed in this publication are those of the author(s) and do not necessarily reflect the views of SAGARPA (SADER) and ARCADIA. Dr. Caiyun Liu's stay at the CIMMYT was sponsored by the China Scholarship Council (CSC)-CIMMYT scholarship.

Compliance with ethics guidelines Caiyun Liu, Francisco Pinto, C. Mariano Cossani, Sivakumar Sukumaran, and Matthew P. Reynolds declare that they have no conflicts of interest or financial conflicts to disclose.

This article does not contain any studies with human or animal subjects performed by any of the authors.

\section{References}

1. Pereira J J. Climate change 2014-impacts, adaptation and vulnerability. Part B: regional aspects. In: Contribution of Working Group II to the Fifth Assessment Report of the IPCC. Cambridge: Cambridge University Press, 2014

2. Prasad P, Boote K, Allen L Jr, Sheehy J, Thomas J. Species, ecotype and cultivar differences in spikelet fertility and harvest index of rice in response to high temperature stress. Field Crops Research, 2006, 95(2-3): 398-411

3. Loss S P, Siddique KHM. Morchological and physiological traits associated with wheat yield increases in Mediterranean environment. In: Sparks D, ed. Advances in Agronomy. San Diego: Academic Press, 1994, 229-276

4. Ferrio J, Villegas D, Zarco J, Aparicio N, Araus J, Royo C. Assessment of durum wheat yield using visible and near-infrared reflectance spectra of canopies. Field Crops Research, 2005, 94(23): $126-148$

5. Reynolds M, Rajaram S, Sayre K. Physiological and genetic changes of irrigated wheat in the post-green revolution period and approaches for meeting projected global demand. Crop Science, 1999, 39(6): 1611-1621

6. Cossani C M, Reynolds M P. Physiological traits for improving heat tolerance in wheat. Plant Physiology, 2012, 160(4): 1710-1718

7. Reynolds M, Pask A, Mullan D. Physiological breeding I: interdisciplinary approaches to improve crop adaptation. Mexico, D.F.: CIMMYT, 2012

8. Tattaris M, Reynolds M P, Chapman S C. A direct comparison of remote sensing approaches for high-throughput phenotyping in plant breeding. Frontiers of Plant Science, 2016, 7: 1131

9. Araus J L, Kefauver S C, Zaman-Allah M, Olsen M S, Cairns J E. Translating high-throughput phenotyping into genetic gain. Trends in Plant Science, 2018, 23(5): 451-466

10. Knipling E B. Physical and physiological basis for the reflectance of visible and near-infrared radiation from vegetation. Remote Sensing of Environment, 1970, 1(3): 155-159

11. Shorter R, Lawn R, Hammer G. Improving genotypic adaptation in crops - a role for breeders, physiologists and modellers. Experimental Agriculture, 1991, 27(2): 155-175

12. Babar M, Van Ginkel M, Klatt A, Prasad B, Reynolds M. The potential of using spectral reflectance indices to estimate yield in wheat grown under reduced irrigation. Euphytica, 2006, 150(1-2): $155-172$

13. Jordan C F. Derivation of leaf-area index from quality of light on the 
forest floor. Ecology, 1969, 50(4): 663-666

14. Rouse J, Haas R, Schell J, Deerin D. Monitoring vegetation systems in the great plains with ERTS. In: NASA. Goddard Space Flight Center 3d ERTS-1 Symposium, College Station. Washington: NASA, 1974, 309-317

15. Gamon J A, Serrano L, Surfus J S. The photochemical reflectance index: an optical indicator of photosynthetic radiation use efficiency across species, functional types, and nutrient levels. Oecologia, 1997, 112(4): 492-501

16. Penuelas J, Gamon J A, Griffin K L, Field C B. Assessing community type, plant biomass, pigment composition, and photosynthetic efficiency of aquatic vegetation from spectral reflectance. Remote Sensing of Environment, 1993, 46(2): 110-118

17. Peñuelas J, Pinol J, Ogaya R, Filella I. Estimation of plant water concentration by the reflectance water index WI (R900/R970). International Journal of Remote Sensing, 1997, 18(13): 2869-2875

18. Sellers P. Canopy reflectance, photosynthesis, and transpiration: II. The role of biophysics in the linearity of their interdependence. Remote Sensing of Environment, 1987, 21(2): 143-183

19. Wiegand C L, Richardson A J. Use of spectral vegetation indices to infer leaf area, evapotranspiration and yield: I. Rationale. Agronomy Journal, 1990, 82(3): 623-629

20. Baret F, Guyot G. Potentials and limits of vegetation indices for LAI and APAR assessment. Remote Sensing of Environment, 1991, 35 (2-3): 161-173

21. Chappelle E W, Kim M S, McMurtrey J E III. Ratio analysis of reflectance spectra (RARS): an algorithm for the remote estimation of the concentrations of chlorophyll a, chlorophyll b, and carotenoids in soybean leaves. Remote Sensing of Environment, 1992, 39(3): 239-247

22. Aparicio N, Villegas D, Araus J, Casadesus J, Royo C. Relationship between growth traits and spectral vegetation indices in durum wheat. Crop Science, 2002, 42(5): 1547-1555

23. Babar M, Reynolds M, Van Ginkel M, Klatt A, Raun W, Stone M. Spectral reflectance to estimate genetic variation for in-season biomass, leaf chlorophyll, and canopy temperature in wheat. Crop Science, 2006, 46(3): 1046-1057

24. Raun W R, Solie J B, Johnson G V, Stone M L, Lukina E V, Thomason W E, Schepers J S. In-season prediction of potential grain yield in winter wheat using canopy reflectance. Agronomy Journal, 2001, 93(1): 131-138

25. Hassan M, Yang M, Rasheed A, Jin X, Xia X, Xiao Y, He Z. Timeseries multispectral indices from unmanned aerial vehicle imagery reveal senescence rate in bread wheat. Remote Sensing, 2018, 10(6): 809

26. Hassan M A, Yang M, Rasheed A, Yang G, Reynolds M, Xia X, Xiao Y, He Z. A rapid monitoring of NDVI across the wheat growth cycle for grain yield prediction using a multi-spectral UAV platform. Plant Science, 2019, 282: 95-103

27. Gizaw S A, Godoy J G V, Pumphrey M O, Carter A H. Spectral reflectance for indirect selection and genome-wide association analyses of grain yield and drought tolerance in North American spring wheat. Crop Science, 2018, 58(6): 2289-2301

28. Gizaw S A, Godoy J G V, Garland-Campbell K, Carter A H. Using spectral reflectance indices as proxy phenotypes for genome-wide association studies of yield and yield stability in Pacific Northwest winter wheat. Crop Science, 2018, 58(3): 1232-1241

29. Wang S, Wong D, Forrest K, Allen A, Chao S, Huang B E, Maccaferri M, Salvi S, Milner S G, Cattivelli L, Mastrangelo A M, Whan A, Stephen S, Barker G, Wieseke R, Plieske J, Lillemo M, Mather D, Appels R, Dolferus R, Brown-Guedira G, Korol A, Akhunova A R, Feuillet C, Salse J, Morgante M, Pozniak C, Luo M C, Dvorak J, Morell M, Dubcovsky J, Ganal M, Tuberosa R, Lawley C, Mikoulitch I, Cavanagh C, Edwards K J, Hayden M, Akhunov E. Characterization of polyploid wheat genomic diversity using a highdensity 90000 single nucleotide polymorphism array. Plant Biotechnology Journal, 2014, 12(6): 787-796

30. Lopes M S, Dreisigacker S, Peña R J, Sukumaran S, Reynolds M P. Genetic characterization of the wheat association mapping initiative (WAMI) panel for dissection of complex traits in spring wheat. Theoretical and Applied Genetics, 2015, 128(3): 453-464

31. Sukumaran S, Dreisigacker S, Lopes M, Chavez P, Reynolds M P. Genome-wide association study for grain yield and related traits in an elite spring wheat population grown in temperate irrigated environments. Theoretical and Applied Genetics, 2015, 128(2): 353-363

32. Sukumaran S, Reynolds M P, Lopes M S, Crossa J. Genome-wide association study for adaptation to agronomic plant density: a component of high yield potential in spring wheat. Crop Science, 2015, 55(6): 2609-2619

33. Reynolds M, Balota M, Delgado M, Amani I, Fischer R. Physiological and morphological traits associated with spring wheat yield under hot, irrigated conditions. Functional Plant Biology, 1994, 21(6): 717-730

34. Birth G S, McVey G R. Measuring the color of growing turf with a reflectance spectrophotometer 1. Agronomy Journal, 1968, 60(6): 640-643

35. Dale $\mathrm{M}$, Causton $\mathrm{D}$. Use of the chlorophyll $\mathrm{a} / \mathrm{b}$ ratio as a bioassay for the light environment of a plant. Functional Ecology, 1992, 6(2): 190-196

36. Chapelle E, Kim M, McMurtrey I. Ratio analysis of reflectance spectra (RARS): an algorithm for the remote estimation of the concentrations of $\mathrm{Chl} \mathrm{a,} \mathrm{b}$ and carotenoids in soybean leaves. Remote Sensing of Environment, 1992, 39: 239-247

37. Gitelson A, Merzlyak M N. Quantitative estimation of chlorophyll-a using reflectance spectra: experiments with autumn chestnut and maple leaves. Journal of Photochemistry and Photobiology B: Biology, 1994, 22(3): 247-252

38. Liu H Q, Huete A. A feedback based modification of the NDVI to minimize canopy background and atmospheric noise. IEEE Transactions on Geoscience and Remote Sensing, 1995, 33(2): 457-465

39. Dash J, Curran P. Evaluation of the MERIS terrestrial chlorophyll index (MTCI). Advances in Space Research, 2007, 39(1): 100-104

40. Blackburn G A. Quantifying chlorophylls and caroteniods at leaf and canopy scales: an evaluation of some hyperspectral approaches. Remote Sensing of Environment, 1998, 66(3): 273-285

41. Gitelson A A, Merzlyak M N, Chivkunova O B. Optical properties and nondestructive estimation of anthocyanin content in plant leaves. Photochemistry and Photobiology, 2001, 74(1): 38-45

42. Rondeaux G, Steven M, Baret F. Optimization of soil-adjusted vegetation indices. Remote Sensing of Environment, 1996, 55(2): 
95-107

43. Haboudane D, Miller J R, Tremblay N, Zarco-Tejada P J, Dextraze L. Integrated narrow-band vegetation indices for prediction of crop chlorophyll content for application to precision agriculture. Remote Sensing of Environment, 2002, 81(2-3): 416-426

44. Gitelson A A, Zur Y, Chivkunova O B, Merzlyak M N. Assessing carotenoid content in plant leaves with reflectance spectroscopy. Photochemistry and Photobiology, 2002, 75(3): 272-281

45. Peñuelas J, Filella I, Biel C, Serrano L, Save R. The reflectance at the $950-970 \mathrm{~nm}$ region as an indicator of plant water status. International Journal of Remote Sensing, 1993, 14(10): 1887-1905

46. Merzlyak M N, Gitelson A A, Chivkunova O B, Rakitin V Y. Nondestructive optical detection of pigment changes during leaf senescence and fruit ripening. Physiologia Plantarum, 1999, 106 (1): 135-141

47. Prasad B, Carver B F, Stone M L, Babar M, Raun W R, Klatt A R. Potential use of spectral reflectance indices as a selection tool for grain yield in winter wheat under great plains conditions. Crop Science, 2007, 47(4): 1426-1440

48. Penuelas J, Filella I, Gamon J A. Assessment of photosynthetic radiation-use efficiency with spectral reflectance. New Phytologist, 1995, 131(3): 291-296

49. Peñuelas J, Filella I, Lloret P, Mun Oz F, Vilajeliu M. Reflectance assessment of mite effects on apple trees. International Journal of Remote Sensing, 1995, 16(14): 2727-2733

50. Vargas M, Combs E, Alvarado G, Atlin G, Mathews K, Crossa J. META: a suite of SAS programs to analyze multienvironment breeding trials. Agronomy Journal, 2013, 105(1): 11-19

51. Yu J, Pressoir G, Briggs W H, Vroh Bi I, Yamasaki M, Doebley J F, McMullen M D, Gaut B S, Nielsen D M, Holland J B, Kresovich S, Buckler E S. A unified mixed-model method for association mapping that accounts for multiple levels of relatedness. Nature Genetics, 2006, 38(2): 203-208

52. Turner S D. qqman: an R package for visualizing GWAS results using Q-Q and manhattan plots. bioRxiv, 2014: 005165

53. Valluru R, Reynolds M P, Davies W J, Sukumaran S. Phenotypic and genome-wide association analysis of spike ethylene in diverse wheat genotypes under heat stress. New Phytologist, 2017, 214(1): 271-283

54. Sukumaran S, Lopes M, Dreisigacker S, Reynolds M. Genetic analysis of multi-environmental spring wheat trials identifies genomic regions for locus-specific trade-offs for grain weight and grain number. Theoretical and Applied Genetics, 2018, 131(4): 985998

55. Araus J L, Slafer G A, Reynolds M P, Royo C. Plant breeding and drought in C3 cereals: what should we breed for? Annals of Botany, 2002, 89(7): 925-940

56. Prasad B, Carver B F, Stone M L, Babar M, Raun W R, Klatt A R. Genetic analysis of indirect selection for winter wheat grain yield using spectral reflectance indices. Crop Science, 2007, 47(4): 14161425

57. Aparicio N, Villegas D, Casadesus J, Araus J L, Royo C. Spectral vegetation indices as nondestructive tools for determining durum wheat yield. Agronomy Journal, 2000, 92(1): 83-91

58. Royo C, Aparicio N, Villegas D, Casadesus J, Monneveux P, Araus J. Usefulness of spectral reflectance indices as durum wheat yield predictors under contrasting Mediterranean conditions. International Journal of Remote Sensing, 2003, 24(22): 4403-4419

59. Condorelli G E, Maccaferri M, Newcomb M, Andrade-Sanchez P, White J W, French A N, Sciara G, Ward R, Tuberosa R. Comparative aerial and ground based high throughput phenotyping for the genetic dissection of NDVI as a proxy for drought adaptive traits in durum wheat. Frontiers of Plant Science, 2018, 9: 893

60. Liu C, Sukumaran S, Claverie E, Sansaloni C, Dreisigacker S, Reynolds M. Genetic dissection of heat and drought stress QTLs in phenology-controlled synthetic-derived recombinant inbred lines in spring wheat. Molecular Breeding, 2019, 39(3): 34

61. Mittler R. Abiotic stress, the field environment and stress combination. Trends in Plant Science, 2006, 11(1): 15-19

62. Jamsheer K M, Laxmi A. Expression of Arabidopsis FCS-Like Zinc finger genes is differentially regulated by sugars, cellular energy level, and abiotic stress. Frontiers of Plant Science, 2015, 6: 746

63. Hwang J U, Song W Y, Hong D, Ko D, Yamaoka Y, Jang S, Yim S, Lee E, Khare D, Kim K, Palmgren M, Yoon H S, Martinoia E, Lee $\mathrm{Y}$. Plant $\mathrm{ABC}$ transporters enable many unique aspects of a terrestrial plant's lifestyle. Molecular Plant, 2016, 9(3): 338-355

64. De Rienzo F, Gabdoulline R R, Menziani M C, Wade R C. Blue copper proteins: a comparative analysis of their molecular interaction properties. Protein Science, 2000, 9(8): 1439-1454

65. Ambawat S, Sharma P, Yadav N R, Yadav R C. MYB transcription factor genes as regulators for plant responses: an overview. Physiology and Molecular Biology of Plants, 2013, 19(3): 307-321

66. McHale L, Tan X, Koehl P, Michelmore R W. Plant NBS-LRR proteins: adaptable guards. Genome Biology, 2006, 7(4): 212 